\title{
DIGITALCOMMONS
}

$5-1-2011$

\section{Front Matter}

JMASM Editors

Follow this and additional works at: http:// digitalcommons.wayne.edu/jmasm

\section{Recommended Citation}

Editors, JMASM (2011) "Front Matter," Journal of Modern Applied Statistical Methods: Vol. 10 : Iss. 1 , Article 1. DOI: $10.22237 /$ jmasm/1304222400

Available at: http://digitalcommons.wayne.edu/jmasm/vol10/iss1/1

This Front Matter is brought to you for free and open access by the Open Access Journals at DigitalCommons@WayneState. It has been accepted for inclusion in Journal of Modern Applied Statistical Methods by an authorized editor of DigitalCommons@WayneState. 


\section{Journal Of Modern Applied Statistical Methods}

Shlomo S. Sawilowsky

Editor

College of Education

Wayne State University

Harvey Keselman

Associate Editor

Department of Psychology

University of Manitoba

Bruno D. Zumbo

Associate Editor

Measurement, Evaluation, \& Research Methodology

University of British Columbia

Vance W. Berger

Assistant Editor

Biometry Research Group

National Cancer Institute

John L. Cuzzocrea

Assistant Editor

Educational Research

University of Akron

Todd C. Headrick

Assistant Editor

Educational Psychology and Special Education

Southern Illinois University-Carbondale

Alan Klockars

Assistant Editor

Educational Psychology

University of Washington 


\section{Journal Of Modern Applied Statistical Methods}

Invited Articles

$2-7$

$8-18$

Regular Articles

$19-28$

$29-50$

$51-60$

$61-66$

$67-76$

$77-96$

$97-109$

$110-115$
Norman Cliff

Rand R. Wilcox

Daniel J. Mundfrom, Jay Schaffer, Myoung-Jin Kim,

Dale Shaw, Ampai Thongteeraparp, Chana Preecha, Pornsin Supawan

Jack C. Hill, Shlomo S. Sawilowsky

Housila P. Singh, Sunil Kumar, Sandeep Bhougal

Rajesh Tailor, Balkishan Sharma

Tze-San Lee

Guili Zhang, James Algina

Gordon P. Brooks, George A. Johanson

Sara Mann, James Chowhan
A Test that Combines Frequency and Quantitative Information

Comparing the Strength of Association of Two Predictors via Smoothers or Robust Regression Estimators

Number of Replications Required in Monte Carlo Simulation Studies: A Synthesis of Four Studies

Bias in Monte Carlo Simulations Due to Pseudo-Random Number Generator Initial Seed Selection

Estimation of Population Mean in Successive Sampling by Sub-Sampling Non-

Respondents

Improved Estimation of the Population Mean Using Known Parameters of an Auxiliary Variable

Matched-Pair Studies with Misclassified Ordinal Data

A Robust Root Mean Square Standardized Effect Size in One Way Fixed-Effects ANOVA

Sample Size Considerations for Multiple Comparison Procedures in ANOVA

Weighting Large Datasets with Complex Sampling Designs: Choosing the Appropriate Variance Estimation Method 


$\begin{array}{ll}116-122 & \text { G. Srinivasa Rao } \\ 123-131 & \text { Ghassen EI Montasse } \\ 132-138 & \begin{array}{l}\text { Tze-San Lee } \\ \text { Ann A. O'Connell, } \\ \text { Xing Liu }\end{array} \\ 139-175 & \begin{array}{l}\text { Xuemei Pan, } \\ \text { C. Mitchell Dayton }\end{array} \\ 176-191 & \begin{array}{l}\text { Ayman Baklizi, } \\ \text { Adil E. Yousif }\end{array} \\ & \\ 198-206 & \text { Sally A. Lesik }\end{array}$

$207-213$

$214-225$

$226-248$

$249-261$

$262-267$
S. N. Martyshenko,

E. A. Egorov

Madhusudan Bhandary, Koji Fujiwara

Amery D. Wu, Bruno D. Zumbo, Linda S. Siegel

Min Liu, Gregory R. Hancock, Jeffrey R. Harring

Mahmoud M. Smadi, M. T. Alodat
Double Acceptance Sampling Plans Based on Truncated Life Tests for Marshall-Olkin Extended Lomax Distribution

The Overall F-tests for Seasonal Unit Roots Under Nonstationary Alternatives: Some Theoretical Results and a Monte Carlo Investigation

Fisher's Exact Test for Misclassified Data

Model Diagnostics for Proportional and Partial Proportional Odds Models

Factors Influencing the Mixture Index of Model Fit in Contingency Tables Showing Independence

Inference in Simple Regression for the Intercept Utilizing Prior Information on the Slope

New Perspectives in Applying the Regression-Discontinuity Design for Program Evaluation: A Simulation Analysis

Information Technology for Increasing Qualitative Information Processing Efficiency

An Exact Test for the Equality of Intraclass Correlation Coefficients Under Unequal Family Sizes

General Piecewise Growth Mixture Model: Word Recognition Development for Different Learners in Different Phases

Using Finite Mixture Modeling to Deal with Systematic Measurement Error: A Case Study

Bayesian Threshold Moving Average Models 
$268-276$

$277-286$

$287-299$

$300-312$

$313-321$

$322-328$

$329-336$

$337-348$

$349-361$
S. P. Ahmad,

A. A. Khan,

A. Ahmed

Miguel A. Padilla, Guili Zhang

Joseph L. Balloun, Hilton Barrett, Art Weinstein

John N. Dyer

Androulla Michaeloudis

James F. Reed III

Ramalingam Shanmugam

Narayan Chanra Sinha, M. Ataharul Islam, Kazi Saleh Ahamed

Ömer Ĕgecioğlu, Ayça Ebru Giritligil
Bayesian Regression Analysis with Examples in S-PLUS and R

Estimating Internal Consistency Using Bayesian Methods

One is Not Enough: The Need for Multiple

Respondents in Survey Research of Organizations

A Simulation Study of the Relative Efficiency of the Minimized Integrated Square Error Estimator (L2E) for Phase I Control Charting

Maximum Likelihood Solution for the Linear Structural Relationship with Three

Parameters Known

Extension of Grizzle's Classic Crossover Design

Is Next Twelve Months Period Tumor Recurrence Free Under Restricted Rate Due to Medication? A Probabilistic Warning

Logistic Regression Models for Higher Order Transition Probabilities of Markov Chain for Analyzing the Occurrences of Daily Rainfall Data

The Likelihood of Choosing the BordaWinner with Partial Preference Rankings of the Electorate
Emerging Scholars $362-372$

$373-402$

*deceased

\begin{abstract}
Albert K. Adusah*, Gordon P. Brooks
\end{abstract}

P. Borysov, Ping Sa
Type I Error Inflation of the SeparateVariances Welch $t$ test with Very Small Sample Sizes when Assumptions Are Met

A Robust One-Sided Variability Control Chart 
$J M A S M$ is an independent print and electronic journal (http://www.jmasm.com/), publishing (1) new statistical tests or procedures, or the comparison of existing statistical tests or procedures, using computer-intensive Monte Carlo, bootstrap, jackknife, or resampling methods, (2) the study of nonparametric, robust, permutation, exact, and approximate randomization methods, and (3) applications of computer programming, preferably in Fortran (all other programming environments are welcome), related to statistical algorithms, pseudorandom number generators, simulation techniques, and self-contained executable code to carry out new or interesting statistical methods.

\section{Editorial Assistant: Julie M. Smith}

